\title{
Recent insight into the correlation of SREBP-mediated lipid metabolism and innate immune response
}

\author{
Hyeon Young Park, Hye Suk Kang and Seung-Soon Im \\ Department of Physiology, Keimyung University School of Medicine, Daegu, South Korea \\ Correspondence should be addressed to S-S Im: ssim73@kmu.ac.kr
}

\begin{abstract}
Fatty acids are essential nutrients that contribute to several intracellular functions. Fatty acid synthesis and oxidation are known to be regulated by sterol regulatory element-binding proteins (SREBPs), which play a pivotal role in the regulation of cellular triglyceride synthesis and cholesterol biogenesis. Recent studies point to a multifunctional role of SREBPs in the pathogenesis of metabolic diseases, such as obesity, type II diabetes and cancer as well as in immune responses. Notably, fatty acid metabolic intermediates are involved in energy homeostasis and pathophysiological conditions. In particular, intracellular fatty acid metabolism affects an inflammatory response, thereby influencing metabolic diseases. The objective of this review is to summarize the recent advances in our understanding of the dual role of SREBPs in both lipid metabolism and inflammation-mediated metabolic diseases.
\end{abstract}

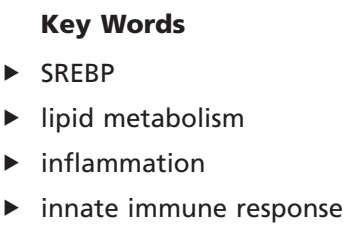

Journal of Molecular Endocrinology (2018) 61, R123-R131

\section{Introduction}

Modern-day dietary habits, featuring high fat and high carbohydrate intake, have triggered global health problems (Popkin et al. 2012). Undoubtedly, these dietary trends have resulted in an epidemic of metabolic diseases that has led to an increase in the number of people living with serious metabolic dysfunctions (e.g., diabetes) as well as cardiovascular diseases (Monteiro \& Azevedo 2010, Han \& Lean 2016).

Cellular lipids and cholesterol are important for the maintenance of a steady-state level of membrane biosynthesis and coordinate many biological processes, such as cell growth and metabolic homeostasis (Muro et al. 2014, Shimano \& Sato 2017). Cellular triglyceride homeostasis and cholesterol metabolism are regulated by sterol regulatory element-binding proteins (SREBPs) (Brown \& Goldstein 1997). SREBPs are synthesized in a precursor form. For activation, the complex of SREBP with SREBP cleavage-activating protein (SCAP) dissociates from insulin-induced genes and relocates from the endoplasmic reticulum (ER) to the Golgi apparatus, where SREBPs are sequentially cleaved by site 1 (S1P) and site 2 (S2P) proteases (Daemen et al. 2013). The nuclear form of SREBP enters the nucleus to act as a transcription factor (Shimano \& Sato 2017). The SREBP family contains SREBP-1a, SREBP-1c and SREBP-2. SREBP-1c is the predominant isoform expressed in the liver, whereas Srebp-1a is highly expressed in cells of the immune system, such as bone marrow-derived macrophages and dendritic cells (Im et al. 2011). Srebp-2 is ubiquitously present in various tissues (Hua et al. 1993). Although there is some functional overlap among SREBP isoforms, SREBP-1a and SREBP-1C are involved in fatty acid (FA) metabolism, 
such as the FA and triacylglycerol (TG) biosynthesis pathways, whereas SREBP-2 is the master regulator of cholesterol synthesis and lipogenesis (Daemen et al. 2013, Xu et al. 2013b).

Recent studies have expanded the list of known functions of SREBP-1 to include systemic biological processes for cellular lipid homeostasis (Jeon \& Osborne 2012). The objective of this review is to summarize the recent advances in our understanding of the functions of SREBP-1 as a bridge between metabolism and the immune system in mammals.

\section{Recent insights into immunometabolism}

Recently, research on immunometabolism, the interplay between immunological and metabolic processes, revealed that specific metabolic activities are required for proper immune-cell differentiation and function $\left(\mathrm{O}^{\prime}\right.$ Neill et al. 2016). Cellular metabolism is important for facilitating the functions of immune cells. Nutrients not only are fuels for metabolic pathways but are also involved in modulating the activity of important regulators of immune metabolism and function (Loftus \& Finlay 2015). In T cells, for example, glutamine deprivation compromises activation-induced $\mathrm{T}$ cell growth and proliferation, and HIF1 and MYC are induced upon T cell activation (Wang et al. 2011), whereas the induction of glutamine uptake and metabolism requires extracellular signal regulated kinase (ERK) function, driving $\mathrm{T}$ cell activation (Carr et al. 2010). Glucose metabolism and mTORC1-HIF1 $\alpha$ signaling are required for neutrophil effector functions like the formation of neutrophil extracellular traps (McInturff et al. 2012).

Metabolic enzymes can have a direct role in the control over immune responses. In myeloid cells, glyceraldehyde 3-phosphate dehydrogenase (GAPDH) involved in glycolysis is a component of the interferon $\gamma$-activated inhibitor of translation (GAIT) complex, which binds defined elements in the 3' untranslated region (UTR) within the family of inflammatory mRNAs and suppresses their translation (Mukhopadhyay et al. 2009). In addition, immune stimuli can cause reprogramming of metabolic pathways. Activation of macrophages with lipopolysaccharide (LPS) disrupts the Krebs cycle, resulting in accumulation of succinate and HIF1 $\alpha$ activation, promoting induction of IL- $1 \beta$ transcription (Tannahill et al. 2013). LPS enhances glycolysis where enzyme hexokinase 1 primes the NLRP3 inflammasome to stimulate pro-IL-1 $\beta$ processing (Moon et al. 2015). Moreover, immune cells can reprogram their cellular metabolism under the influence of significant metabolic stressors caused by altered microenvironments and function in immunity. Altered glutamine metabolism, e.g., glutamine deprivation or inhibition of N-glycosylation, decreases M2 polarization of macrophages (Jha et al. 2015). Glycolysis is needed for the functioning of Th17 cells as inflammatory lymphocytes; when glycolysis is blocked in $\mathrm{T}$ cells, they become regulatory $\mathrm{T}$ cells serving as anti-inflammatory regulators (Buck et al. 2015).

Immune cells with different functions use distinct metabolic pathways to ensure energy homeostasis and to control molecular biosynthesis for growth and proliferation (Loftus \& Finlay 2015). As one example, activated lymphocytes after stimulation through antigen or cytokine receptors maintain aerobic glycolysis increasing the rates of both glycolysis and oxidative phosphorylation, but mature myeloid cells tend to be non-proliferative and thus employ aerobic glycolysis (Loftus \& Finlay 2015).

Many studies have successfully shown connections among metabolism, immunity and inflammation at the intracellular level (Ertunc \& Hotamisligil 2016, Buck et al. 2017). Early immunometabolism studies described the metabolic demands for the function of immune cells (Oren et al. 1963, Newsholme et al. 1986). One research group demonstrated that the main inflammatory signaling pathway, which involves nuclear factor $\kappa \mathrm{B}$ (NF- $\mathrm{kB}$ ) and the inhibitor of $\kappa \mathrm{B}$ kinase $\beta$ (IKK $\beta$ ), is stimulated in obesity and insulin resistance (Shoelson et al. 2003). In addition, it was revealed that c-Jun N-terminal protein kinases (JNKs) are activated as pro-inflammatory factors during obesity-related inflammation (Hirosumi et al. 2002). Collectively, these findings highlight the tight connection of metabolism and inflammation, giving rise to an entirely new field of biomedical research referred to as immunometabolism (Mraz \& Haluzik 2014).

\section{The relation between lipids and inflammation}

Lipids play pivotal roles in metabolism, immunity and cancer as inflammatory mediators. Indeed, cholesterol, FAs and modified lipids can directly activate inflammatory pathways. Adipokines are also involved in inflammatory processes (Asrih \& Jornayvaz 2013). Production of most adipokines is upregulated in the obese state, and these pro-inflammatory proteins typically function to promote obesity-associated metabolic diseases. TNFa and IL- 6 are among the more recently identified adipokines including resistin, retinol-binding protein 4 (RBP4), lipocalin 2 (LCN2), IL-18, angiopoietin-like protein 2 (ANGPTL2), 
CC-chemokine ligand 2 (CCL2), CXC-chemokine ligand 5 (CXCL5) and nicotinamide phosphoribosyltransferase (NAMPT) (Ouchi et al. 2011). Leptin is an adipokine synthesized primarily by the white adipose tissue, but also expressed in the immune cells that exert relevant actions both on metabolism and the immune system (Abella et al. 2017). Leptin participates in innate immunity by inhibiting natural killer (NK) cells immune functions and NK cells proliferation (Wrann et al. 2012) and increasing the expression of monocyte surface markers (Conde et al. 2010). Leptin is involved in the adaptive immune system by enhancing proliferation and responsiveness of regulatory $\mathrm{T}$ cells (De Rosa et al. 2007) and by activating B cells to induce secretion of IL-6, IL-10 and TNFa (Agrawal et al. 2011). Moreover, leptin exerts its pro-inflammatory and pro-catabolic actions on cartilage and triggers degeneration of articular cartilage, which is characteristic of osteoarthritis (Dumond et al. 2003). In addition to the numerous pro-inflammatory adipokines described earlier, adipose tissues secrete a few antiinflammatory factors, such as adiponectin and SFRP5, which were recently identified as adipokines (Ouchi et al. 2003, Berg \& Scherer 2005, Ouchi et al. 2010). Adiponectin levels in plasma and adipose tissue are lower in obese individuals compared with lean individuals (Ryo et al. 2004). Consistent with decreased adiponectin level in obesity, the production of adiponectin in adipocytes is inhibited by pro-inflammatory factors, such as TNFa and IL-6, as well as by hypoxia and oxidative stress (Hosogai et al. 2007).

The liver is an important metabolic organ that responds to energy imbalances and performs a key function in lipid homeostasis (Canbay et al. 2007). Ectopic fat accumulation in the liver and the subsequent hepatic insulin resistance cause either local inflammation mediated by the liver or systematic inflammation mediated by white adipose tissue (WAT) (Asrih \& Jornayvaz 2013). Previously, WAT has been regarded as a static storage site for excess energy or as a material for thermal and mechanical insulation of the body. Nonetheless, WAT has emerged as a dynamic tissue for the integration of metabolic, endocrine and immune functions that participates in whole-body homeostasis, which is maintained by an orchestrated interplay of immune cells and chemical signals (Mraz \& Haluzik 2014, Maurizi et al. 2018).

In macrophages, lipid metabolism can trigger inflammation. Studies in hyperlipidemic mouse models suggest that high circulating levels of chylomicrons, very low-density lipoprotein and their remnants induce hepatic inflammation via enhanced scavenger receptor-mediated uptake of these lipoproteins by Kupffer cells (KCs; i.e., liver tissue-resident macrophages), thereby triggering an inflammatory response in the liver (van Diepen et al. 2013). In addition, macrophage-specific genetic ablation of a fatty acid-binding protein (FABP4, also known as aP2) suppresses inflammatory signaling and attenuates activation of the NF-кB pathway (Xu et al. 2015). Furthermore, KCs are involved in an important mechanism underlying nonalcoholic fatty liver disease (NAFLD) (Smith 2013, Wan et al. 2014). In the early stages of the disease, $\mathrm{KC}$ population expands rapidly, and $\mathrm{KCs}$ secrete cytokines and chemokines such as IL-1 $\beta$, TNF $\alpha$, CCL2 and CCL5, contributing to paracrine activation of protective or apoptotic signaling pathways in hepatocytes and to the recruitment of other immune cells (Dixon et al. 2013). In the KCs of rats with NAFLD, liver $X$ receptor $\alpha(\mathrm{LXR} \alpha)$, SREBP-1c and fatty acid synthase (FAS) mRNA and protein levels are elevated, indicating that high-fat diet (HFD)-induced high LXR $\alpha$ levels may increase Fas expression through activation of the SREBP-1c pathway (Gong et al. 2014). In obesity, during an HFD, KCs are polarized to M1 activation (which represents proinflammatory macrophages) and are reported to augment hepatic inflammation and consequently accelerate hepatic steatosis (McArdle et al. 2013). KCs are responsive not only to inflammatory signals but also to metabolic fluctuations. As mentioned earlier, lipids per se and highenergy diets can be harmful to the liver. Evidence shows that an overload of lipids and cholesterol derivatives activates KCs in the fatty liver disease and steatohepatitis (Dixon et al. 2013). In vitro stimulation of mouse KCs with saturated fatty acids (SFAs) upregulates toll-like receptors (TLRs) (Tang et al. 2013). Thus, free FA sensing by KCs may condition their responsiveness to pro-inflammatory triggers.

It is well known that FAs are transported to various organs including the liver and skeletal muscle under physiological conditions; thereafter, FAs are broken down through $\beta$-oxidation in the mitochondria or are stored as TGs (Rambold et al. 2015). Notably, stored hepatic TGs predominantly originate from the lipolysis of TGs released from WAT. Dietary FAs and de novo lipogenesis are the major sources of other lipid stores (Asrih \& Jornayvaz 2013, Saponaro et al. 2015). Imbalances between complex pathways lead to excessive FA flux and accumulation. Downstream products, including fatty acylcoenzyme A, diacylglycerol and ceramides, mediate the lipotoxic effects, resulting in several metabolic diseases, e.g., obesity and diabetes (Jornayvaz \& Shulman 2012, Asrih \& Jornayvaz 2013). Indeed, these pathology-related 
lipid species have been shown to interfere with signaling via modulation of serine/threonine kinases, such as protein kinase $\mathrm{C}$, JNK, IKK and the mechanistic target of rapamycin (mTOR), thus indicating lipid-induced insulin resistance and promoting inflammation, apoptosis and hypertrophy (Ritchie et al. 2017).

FAs have also been shown to modulate $\mathrm{T}$ cell function and specific functions of innate and acquired immunity (De Jong et al. 2014, Whelan et al. 2016). High levels of n-3 poly unsaturated fatty acids (PUFAs) to healthy animals or human subjects results in suppression of the ability of lymphocytes to respond to mitogen stimulation, NK cell activity and delayed type hypersensitivity reactions (Kew et al. 2004). Immunomodulatory effects of n-3 PUFA enhance eicosanoid formation, signal transduction, gene expression and lipid peroxidation. Long-chain n-3 PUFAs, such as eicosapentaenoic and docosahexaenoic acids (EPA and DHA) influence proliferation, maturation and differentiation of lymphocytes through decrease of diacylglyceride and ceramide levels and decrease of IL-2 mRNA expression and secretion. Since n-3 PUFA antagonizes the stimulation of inflammatory response, there is potential for benefit in asthma and chronic inflammatory diseases (Calder 2010). The pathogenesis of NAFLD is known to involve inflammatory signaling pathways such as NF-kB/IKK $\beta$, JNK and mitogen-activated protein kinase (MAPK) cascades (Yang et al. 2012, Zeng et al. 2014).

FA oxidation and FA synthesis have different roles in the immune system. FA oxidation is associated with the differentiation of macrophages toward the anti-inflammatory M2 phenotype and formation of inflammation-suppressing regulatory $\mathrm{T}$ cells, which subsequently increase the expression of FA oxidationrelated genes, including carnitine O-palmitoyltransferase 1 alpha (CPT1a). Constitutively active CPT1a increases FA oxidation and reduces the production of inflammatory cytokines and lipid accumulation (Patsoukis et al. 2015, O'Neill et al. 2016). On the other hand, FA synthesis is related to the formation and function of pro-inflammatory immune cells. Several studies show that enhanced FA synthesis in macrophages is triggered by inflammatory stimuli (Calder 2010, Ecker et al. 2010, Kelly \& O'Neill 2015). In addition, the cytokines being made by Th17 cells depend on the type of FA being synthesized. For example, production of IL-10, an anti-inflammatory cytokine, is promoted when polyunsaturated FAs are present but is limited when SFAs are present. In other words, SFAs and polyunsaturated FAs lead to opposite inflammatory responses through recognition by distinct receptors. SFAs trigger a pro-inflammatory response through TLR4 receptor, and polyunsaturated FAs engage G protein-coupled receptor 120 (GPR120) to induce an anti-inflammatory signaling cascade (Osborn et al. 2012). At the same time, lipid metabolism disorders are mediated by the LXR $\alpha$ /SREBP-1c signaling pathway in liver tissue during NAFLD (He et al. 2011, Xu et al. 2013a). Because FAs substantially participate in the development of NAFLD, targeting of lipid synthesis is considered a therapeutic strategy to prevent hepatic steatosis (Asrih \& Jornayvaz 2013).

FA and cholesterol homeostasis are tightly controlled at the level of transcription by LXRs and SREBPs (Oishi et al. 2017). Both sterols and oxysterols reconsidered for their fundamental activity as ligands of SREBP and LXR are elevated in metabolic disorders and influence immune cell function (Cagno et al. 2017). Oxysterols are a family of cholesterol oxidation and derivative mainly 25-hydroxycholesterol (25-HC), 27-hydroxycholesterol (27-HC) and 24-hydroxycholesterol (24-HC). In nonalcoholic steatohepatitis, 27-HC reduces accumulation of cholesterol in lysosomes of KCs to promote an antiinflammatory phenotype (Bieghs et al. 2013, Hendrikx et al. 2015). Elevations in 27-HC via deletion of cytochrome P450 family 27 subfamily B polypeptide 1 (CYP7B1), which functioned in the metabolism of cholesterol metabolites, such as $27-\mathrm{HC}$ promote atherosclerosis in apoE-deficient atherosclerotic mouse model (Umetani et al. 2014). Similarly, in monocyte/macrophages $27-\mathrm{HC}$ negatively impacts bone homeostasis via activation of LXR, which inhibits osteoblast differentiation and increases the TNFa expression (Nelson et al. 2011).

Srebp-1a and Lxra are highly expressed in macrophages and known regulators of cytokine release from macrophages (Joseph et al. 2004, Worby \& Dixon 2011). Srebp-1 KO macrophages exhibited reduced production of anti-inflammatory FAs (Hien et al. 2017). In other reports, bacterial alpha-toxin-induced SREBP-1a activates lipogenesis and the anti-apoptotic factor Api6 gene following bacterial infection of macrophages, which provides protection from apoptosis induced by bacterial toxins (Tie et al. 2012). Similar late hyper-inflammatory trends were observed in Srebp-1 KO macrophages stimulated with ligands for TLR2 and TLR3. Therefore, Srebp-1 is genetically required for the normal resolution phase in macrophages (Hien et al. 2017). LPS treatment increases SREBP-1a activity and de novo synthesis of cholesteryl esters and triglycerides in peritoneal macrophages (Posokhova et al. 2008). Consistent with these findings, LPS challenges in Srebp-1a-deficient bone 
marrow-derived macrophages are protected against LPS-induced IL-1 $\beta$ production (Im et al. 2011). Im et al. showed that SREBP-1a required for the expression of the inflammasome components inducing the cleavage of inflammatory cytokines pro-IL- $1 \beta$ and pro-IL-18, which are necessary for the production of mature cytokines and secretion of IL-1 $\beta$ in response to systemic inflammation such as endotoxic shock (Franchi et al. 2009, Im et al. 2011). These findings indicate that SREBP activation is linked to an M1 phenotype in macrophages (Hubler \& Kennedy 2016). Given the importance of SREBP in mediating inflammation, it is not surprising that SREBPs have evolved as 'metabolic integrators' that effectively bridge broader physiological processes with basic intermediary lipid metabolism (Kloet et al. 2012).

SREBPs are major transcription factors that regulate cellular lipid metabolism and homeostasis (Horton et al. 2002). During fasting, Srebp-1c expression is low in the liver but dramatically increases after feeding; this increase is mediated by insulin ( $\mathrm{Xu}$ et al. 2013b). In states of energy abundance, protein kinase B (AKT)-mTOR-SREBP signaling increases lipogenesis (Asrih \& Jornayvaz 2013). Lipid-mediated cellular stress (lipotoxicity) caused by SREBP-1 activation contributes to metabolic diseases such as obesity, diabetes mellitus, dyslipidemia and hepatosteatosis, thereby aggravating SREBP-related pathology such as inflammation and fibrosis (Fig. 1) (Shimano \& Sato 2017).

In many studies, researchers have tried to link lipid metabolism to an immune response. For instance, GPR40 and GPR120, which are members of the G protein-coupled receptor (GPCR) family, are involved in anti-inflammatory processes in macrophages, and currently, there is emerging interest in their metabolic effects. These receptors are associated with obesity, insulin responses and subsequent inflammation (Agrawal et al. 2017). According to studies on human subjects, fasting insulin and glucose levels are linked to protein tyrosine phosphatase receptor J (PTPRJ), which is a regulator of $\mathrm{T}$ cell signaling (Manning et al. 2012), and the variant of ST6GAL1 involved in antigen production is associated with susceptibility to type 2 diabetes mellitus (Kooner et al. 2011). Nonetheless, so far, the exact mechanism and function of SREBPs in the immune system remain to be discovered.

SREBP-1a and SREBP-2 are known to play an important role in phagocytosis by promoting membrane biogenesis to compensate for the loss of the plasma membrane when the cell engulfs particles, such as bacteria (Shao \& Espenshade 2012). Notably, Srebp-1a is highly expressed in immune cells and is involved in the activation of a lipogenic gene, such as FAS, acetyl-CoA carboxylase (ACC) and stearoylCoA desaturase-1 (SCD-1), and nucleotide-binding oligomerisation domain, leucinerich repeat proteins $1 \mathrm{a}$ (NLRP1a), a core inflammasome component (Im et al. 2011). Moreover, a recent study revealed that SREBP-1 promotes TLR4-induced gene activation and reprograms macrophage lipid metabolism, including biosynthesis of anti-inflammatory FAs, resulting in the resolution of inflammatory responses (Oishi et al. 2017). Nevertheless, SREBP-1c enhances the nonesterified-fatty acid-induced

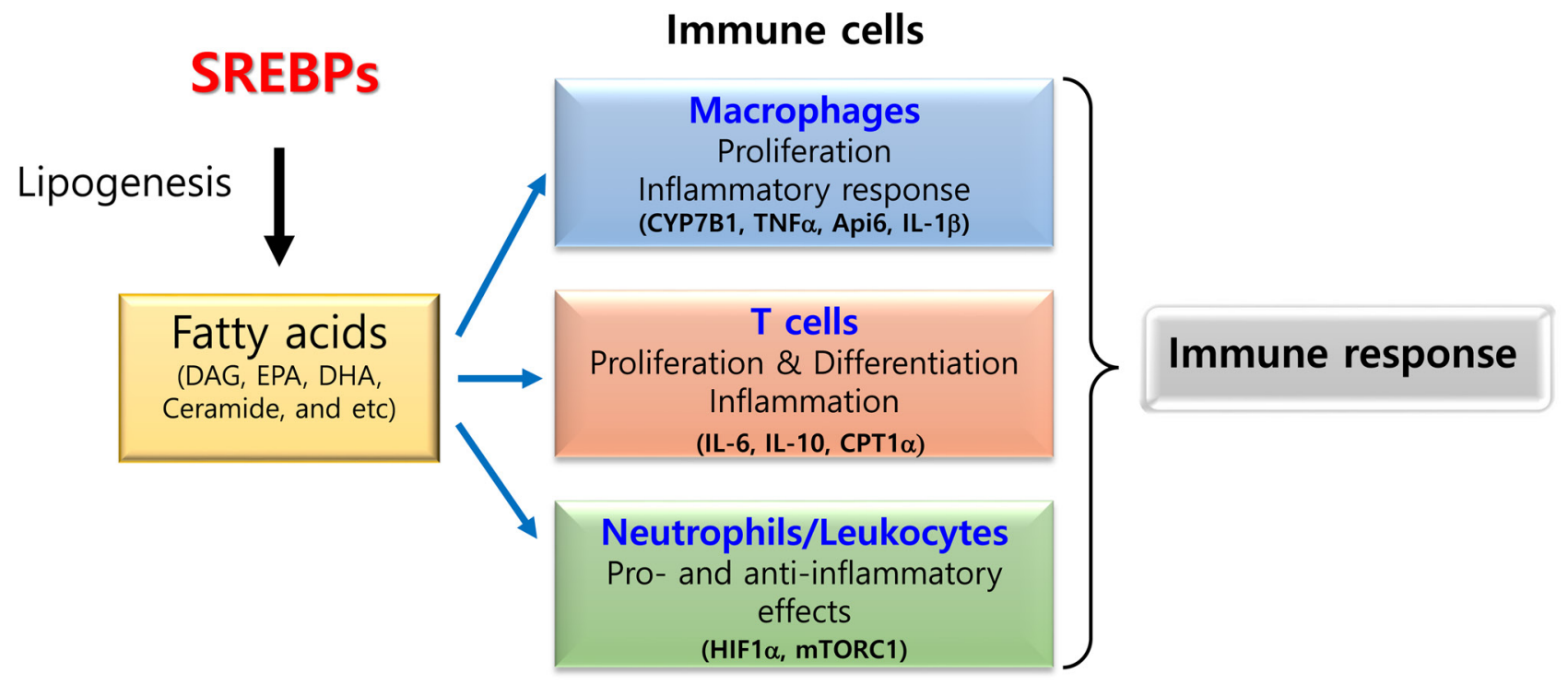

Figure 1

Regulation of metabolic diseases through inflammation by SREBP. 
overactivation of the NF- $\mathrm{kB}$ inflammatory pathway by increasing production of reactive oxygen species. This signaling is not promoted through TLR4, which triggers further hepatic inflammatory damage in dairy cows with fatty liver (Li et al. 2015). In addition, hepatic steatosis and activation of the hepatic IKK $\alpha / \mathrm{NF}-\mathrm{kB}$ inflammatory pathways are observed in Srebp-1c-overexpressing mice (Li et al. 2015). In HFD-induced NAFLD animal model, both sulfated oxysterol and 5-cholesten-3 $\beta$-25-diol 3 -sulfate (25HC3S) reduce lipid accumulation in serum and liver and also suppress lipid-induced inflammation in the liver. Therefore, $25 \mathrm{HC} 3 \mathrm{~S}$ may be a potent endogenous regulator that suppresses the SREBP-1c signaling pathway (Xu et al. 2013a).

SREBPs perform broader functions in cell metabolism and act as regulators of essential lipid homeostasis (Desvergne et al. 2006, Daemen et al. 2013). On the other hand, SREBPs are regulated by diverse mechanisms in different tissues (Goldstein et al. 2006, Shao \& Espenshade 2012). As mentioned earlier, recent studies revealed more varied roles for SREBPs in lipid metabolism and in immune responses (Oishi et al. 2017). Some studies have raised several questions about the participation of SREBPs in immunometabolism, fibrometabolism and mitochondrial function; about the relation between endogenous or exogenous FAs and cholesterol and about the role of nutrients and metabolites in the regulation of SREBP-1 maturation.

\section{Conclusions}

Future studies will focus on deepening our molecular understanding of the immune-metabolic cross-talk. Interventions targeting key molecules in these immunemetabolic interactions may be utilized to modify immune contributions to metabolic diseases. An understanding of the immune-metabolic cross-talk at the molecular level may shed light on the forces that determine immune and metabolic homeostasis and the pathogenesis of immunesystem-mediated or -associated metabolic diseases.

\section{Declaration of interest}

The authors declare that there is no conflict of interest that could be perceived as prejudicing the impartiality of this review.

\section{Funding}

This study was supported by the Korea Research Foundation, Medical Research Center (grant number 2014R1A5A2010008) and by the NRF funded by the Korean Government (MSIP) (grant number 2016R1A2B4008516 to S S I).

\begin{tabular}{|lr}
\hline $\begin{array}{l}\text { http://jme.endocrinology-journals.org } \\
\text { https://doi.org/10.1530/JME-17-0289 }\end{array}$ & ○ 2018 Society for Endocrinology \\
Published by Bioscientifica Ltd. \\
Printed in Great Britain
\end{tabular}

\section{Acknowledgements}

The authors apologize to all contributors in the field of SREBPs whose work due to space limitations could not be cited.

\section{References}

Abella V, Scotece M, Conde J, Pino J, Gonzalez-Gay MA, Gómez-Reino JJ, Mera A, Lago F, Gómez R \& Gualillo O 2017 Leptin in the interplay of inflammation, metabolism and immune system disorders. Nature Reviews Rheumatology 13 100. (https://doi.org/10.1038/ nrrheum.2016.209)

Agrawal S, Gollapudi S, Su H \& Gupta S 2011 Leptin activates human B cells to secrete TNF- $\alpha$, IL-6, and IL-10 via JAK2/STAT3 and p38MAPK/ ERK1/2 signaling pathway. Journal of Clinical Immunology $\mathbf{3 1}$ 472-478. (https://doi.org/10.1007/s10875-010-9507-1)

Agrawal A, Alharthi A, Vailati-Riboni M, Zhou Z \& Loor JJ 2017 Expression of fatty acid sensing G-protein coupled receptors in peripartal Holstein cows. Journal of Animal Science and Biotechnology $\mathbf{8}$ 20. (https://doi.org/10.1186/s40104-017-0150-z)

Asrih M \& Jornayvaz FR 2013 Inflammation as a potential link between nonalcoholic fatty liver disease and insulin resistance. Journal of Endocrinology 218 R25-R36. (https://doi.org/10.1530/JOE-13-0201)

Berg AH \& Scherer PE 2005 Adipose tissue, inflammation, and cardiovascular disease. Circulation Research 96 939-949. (https://doi. org/10.1161/01.RES.0000163635.62927.34)

Bieghs V, Hendrikx T, van Gorp PJ, Verheyen F, Guichot YD, Walenbergh SMA, Jeurissen MLJ, Gijbels M, Rensen SS, Bast A, et al. 2013 The cholesterol derivative 27-hydroxycholesterol reduces steatohepatitis in mice. Gastroenterology 144 167.e161-178.e161. (https://doi.org/10.1053/j.gastro.2012.09.062)

Brown MS \& Goldstein JL 1997 The SREBP pathway: regulation of cholesterol metabolism by proteolysis of a membrane-bound transcription factor. Cell 89 331-340. (https://doi.org/10.1016/S00928674(00)80213-5)

Buck MD, O'Sullivan D \& Pearce EL 2015 T cell metabolism drives immunity. Journal of Experimental Medicine 212 1345-1360. (https:// doi.org/10.1084/jem.20151159)

Buck MD, Sowell RT, Kaech SM \& Pearce EL 2017 Metabolic instruction of immunity. Cell 169 570-586. (https://doi.org/10.1016/j. cell.2017.04.004)

Cagno V, Civra A, Rossin D, Calfapietra S, Caccia C, Leoni V, Dorma N, Biasi F, Poli G \& Lembo D 2017 Inhibition of herpes simplex-1 virus replication by 25-hydroxycholesterol and 27-hydroxycholesterol. Redox Biology 12 522-527. (https://doi.org/10.1016/j. redox.2017.03.016)

Calder PC 2010 Omega-3 fatty acids and inflammatory processes. Nutrients 2 355-374. (https://doi.org/10.3390/nu2030355)

Canbay A, Bechmann L \& Gerken G 2007 Lipid metabolism in the liver. Zeitschrift fur Gastroenterologie 45 35-41. (https://doi. org/10.1055/s-2006-927368)

Carr EL, Kelman A, Wu GS, Gopaul R, Senkevitch E, Aghvanyan A, Turay AM \& Frauwirth KA 2010 Glutamine uptake and metabolism are coordinately regulated by ERK/MAPK during T lymphocyte activation. Journal of Immunology 185 1037-1044. (https://doi. org/10.4049/jimmunol.0903586)

Conde J, Scotece M, Gomez R, Gomez-Reino JJ, Lago F \& Gualillo O 2010 At the crossroad between immunity and metabolism: focus on leptin. Expert Review of Clinical Immunology 6 801-808. (https://doi. org/10.1586/eci.10.48)

Daemen S, Kutmon M \& Evelo CT 2013 A pathway approach to investigate the function and regulation of SREBPs. Genes and Nutrition 8 289-300.

de Jong AJ, Kloppenburg M, Toes RE \& Ioan-Facsinay A 2014 Fatty acids, lipid mediators, and T-cell function. Frontiers in Immunology 5483 (https://doi.org/10.3389/fimmu.2014.00483) 
De Rosa V, Procaccini C, Cali G, Pirozzi G, Fontana S, Zappacosta S, La Cava A \& Matarese G 2007 A key role of leptin in the control of regulatory T cell proliferation. Immunity 26 241-255. (https://doi. org/10.1016/j.immuni.2007.01.011)

Desvergne B, Michalik L \& Wahli W 2006 Transcriptional regulation of metabolism. Physiological Reviews 86 465-514. (https://doi. org/10.1152/physrev.00025.2005)

Dixon LJ, Barnes M, Tang H, Pritchard MT \& Nagy LE 2013 Kupffer cells in the liver. Comprehensive Physiology 3 785-797.

Dumond H, Presle N, Terlain B, Mainard D, Loeuille D, Netter P \& Pottie P 2003 Evidence for a key role of leptin in osteoarthritis. Arthritis and Rheumatology 48 3118-3129. (https://doi.org/10.1002/ art.11303)

Ecker J, Liebisch G, Englmaier M, Grandl M, Robenek H \& Schmitz G 2010 Induction of fatty acid synthesis is a key requirement for phagocytic differentiation of human monocytes. PNAS 1077817. (https://doi.org/10.1073/pnas.0912059107)

Ertunc ME \& Hotamisligil GS 2016 Lipid signaling and lipotoxicity in metaflammation: indications for metabolic disease pathogenesis and treatment. Journal of Lipid Research 57 2099-2114. (https://doi. org/10.1194/jlr.R066514)

Franchi L, Eigenbrod T, Munoz-Planillo R \& Nunez G 2009 The inflammasome: a caspase-1-activation platform that regulates immune responses and disease pathogenesis. Nature Immunology 10 241-247. (https://doi.org/10.1038/ni.1703)

Goldstein JL, DeBose-Boyd RA \& Brown MS 2006 Protein sensors for membrane sterols. Cell 124 35-46. (https://doi.org/10.1016/j. cell.2005.12.022)

Gong X-W, Li H, Yang Q-H, Yan H-Z, Zhang Y-P, Li Y-Y, Xu Y-J, Wang H, Zhang J-W \& Lin C-M 2014 Effects of soothing liver and invigorating spleen recipe on lipid metabolism disorders in kupffer cells of NAFLD rats by LXR $\alpha /$ SREBP-1c signal pathway. Chinese Herbal Medicines 6 297-304. (https://doi.org/10.1016/S16746384(14)60045-9)

Han TS \& Lean MEJ 2016 A clinical perspective of obesity, metabolic syndrome and cardiovascular disease. JRSM Cardiovascular Disease 5 2048004016633371. (https://doi.org/10.1177/2048004016652314)

He XM, Yang QH, Li PF, Chen Z, Feng GF, Wang WJ, Liu HT, Zhang YP \& Ji GY 2011 Effect of soothing liver and invigorating spleen recipes on SREBP-1c mRNA and protein expression in hepatic tissues of rats with non-alcoholic fatty liver disease. Zhong Yao Cai 34 931-937.

Hendrikx T, Jeurissen ML, Bieghs V, Walenbergh SM, van Gorp PJ, Verheyen F, Houben T, Guichot YD, Gijbels MJ, Leitersdorf E, et al. 2015 Hematopoietic overexpression of Cyp27a1 reduces hepatic inflammation independently of 27-hydroxycholesterol levels in Ldlr(-/-) mice. Journal of Hepatology 62 430-436. (https://doi. org/10.1016/j.jhep.2014.09.027)

Hien HTM, Ha NC, Thom LT \& Hong DD 2017 Squalene promotes cholesterol homeostasis in macrophage and hepatocyte cells via activation of liver X receptor (LXR) alpha and beta. Biotechnology Letters 39 1101-1107. (https://doi.org/10.1007/s10529-017-2345-y)

Hirosumi J, Tuncman G, Chang L, Gorgun CZ, Uysal KT, Maeda K, Karin M \& Hotamisligil GS 2002 A central role for JNK in obesity and insulin resistance. Nature 420 333-336. (https://doi.org/10.1038/ nature01137)

Horton JD, Goldstein JL \& Brown MS 2002 SREBPs: activators of the complete program of cholesterol and fatty acid synthesis in the liver. Journal of Clinical Investigation 109 1125-1131. (https://doi. org/10.1172/JCI0215593)

Hosogai N, Fukuhara A, Oshima K, Miyata Y, Tanaka S, Segawa K, Furukawa S, Tochino Y, Komuro R, Matsuda M, et al. 2007 Adipose tissue hypoxia in obesity and its impact on adipocytokine dysregulation. Diabetes 56 901-911. (https://doi.org/10.2337/db060911)

Hua X, Yokoyama C, Wu J, Briggs MR, Brown MS, Goldstein JL \& Wang X 1993 SREBP-2, a second basic-helix-loop-helix-leucine zipper protein that stimulates transcription by binding to a sterol regulatory element. PNAS 90 11603-11607. (https://doi.org/10.1073/ pnas.90.24.11603)

Hubler MJ \& Kennedy AJ 2016 Role of lipids in the metabolism and activation of immune cells. Journal of Nutritional Biochemistry 34 1-7. (https://doi.org/10.1016/j.jnutbio.2015.11.002)

Im SS, Yousef L, Blaschitz C, Liu JZ, Edwards RA, Young SG, Raffatellu M \& Osborne TF 2011 Linking lipid metabolism to the innate immune response in macrophages through sterol regulatory element binding protein-1a. Cell Metabolism 13 540-549. (https://doi.org/10.1016/j. cmet.2011.04.001)

Jeon TI \& Osborne TF 2012 SREBPs: metabolic integrators in physiology and metabolism. Trends in Endocrinology and Metabolism 23 65-72. (https://doi.org/10.1016/j.tem.2011.10.004)

Jha AK, Huang SC, Sergushichev A, Lampropoulou V, Ivanova Y, Loginicheva E, Chmielewski K, Stewart KM, Ashall J, Everts B, et al. 2015 Network integration of parallel metabolic and transcriptional data reveals metabolic modules that regulate macrophage polarization. Immunity 42 419-430. (https://doi.org/10.1016/j. immuni.2015.02.005)

Jornayvaz FR \& Shulman GI 2012 Diacylglycerol activation of protein kinase Cepsilon and hepatic insulin resistance. Cell Metabolism 15 574-584. (https://doi.org/10.1016/j.cmet.2012.03.005)

Joseph SB, Bradley MN, Castrillo A, Bruhn KW, Mak PA, Pei L, Hogenesch J, O'Connell R M, Cheng G, Saez E, et al. 2004 LXRdependent gene expression is important for macrophage survival and the innate immune response. Cell 119 299-309. (https://doi. org/10.1016/j.cell.2004.09.032)

Kelly B \& O'Neill LAJ 2015 Metabolic reprogramming in macrophages and dendritic cells in innate immunity. Cell Research 25771. (https://doi.org/10.1038/cr.2015.68)

Kew S, Mesa MD, Tricon S, Buckley R, Minihane AM \& Yaqoob P 2004 Effects of oils rich in eicosapentaenoic and docosahexaenoic acids on immune cell composition and function in healthy humans. The American Journal of Clinical Nutrition 79 674-681. (https://doi. org/10.1093/ajcn/79.4.674)

Kloet SL, Whiting JL, Gafken P, Ranish J \& Wang EH 2012 Phosphorylation-dependent regulation of cyclin D1 and cyclin A gene transcription by TFIID subunits TAF1 and TAF7. Molecular and Cellular Biology 32 3358-3369. (https://doi.org/10.1128/ MCB.00416-12)

Kooner JS, Saleheen D, Sim X, Sehmi J, Zhang W, Frossard P, Been LF, Chia KS, Dimas AS, Hassanali N, et al. 2011 Genome-wide association study in individuals of South Asian ancestry identifies six new type 2 diabetes susceptibility loci. Nature Genetics 43 984-989. (https://doi.org/10.1038/ng.921)

Li X, Huang W, Gu J, Du X, Lei L, Yuan X, Sun G, Wang Z, Li X \& Liu G 2015 SREBP-1c overactivates ROS-mediated hepatic NF-kappaB inflammatory pathway in dairy cows with fatty liver. Cell Signalling 27 2099-2109. (https://doi.org/10.1016/j.cellsig.2015.07.011)

Loftus RM \& Finlay DK 2015 Immunometabolism; cellular metabolism turns immune regulator. Journal of Biological Chemistry 291 1-10. (https://doi.org/10.1074/jbc.R115.693903)

Manning AK, Hivert MF, Scott RA, Grimsby JL, Bouatia-Naji N, Chen H, Rybin D, Liu CT, Bielak LF, Prokopenko I, et al. 2012 A genome-wide approach accounting for body mass index identifies genetic variants influencing fasting glycemic traits and insulin resistance. Nature Genetics 44 659-669. (https://doi.org/10.1038/ng.2274)

Maurizi G, Della Guardia L, Maurizi A \& Poloni A 2018 Adipocytes properties and crosstalk with immune system in obesity-related inflammation. Journal of Cellular Physiology 233 88-97. (https://doi. org/10.1002/jcp.25855)

McArdle MA, Finucane OM, Connaughton RM, McMorrow AM \& Roche HM 2013 Mechanisms of obesity-induced inflammation and insulin resistance: insights into the emerging role of nutritional strategies. Frontiers in Endocrinology 452. 
McInturff AM, Cody MJ, Elliott EA, Glenn JW, Rowley JW, Rondina MT \& Yost CC 2012 Mammalian target of rapamycin regulates neutrophil extracellular trap formation via induction of hypoxiainducible factor 1 alpha. Blood 120 3118-3125. (https://doi. org/10.1182/blood-2012-01-405993)

Monteiro R \& Azevedo I 2010 Chronic inflammation in obesity and the metabolic syndrome. Mediators of Inflammation 2010289645.

Moon JS, Lee S, Park MA, Siempos, II, Haslip M, Lee PJ, Yun M, Kim CK, Howrylak J, Ryter SW, et al. 2015 UCP2-induced fatty acid synthase promotes NLRP3 inflammasome activation during sepsis. Journal of Clinical Investigation 125 665-680. (https://doi.org/10.1172/JCI78253)

Mraz M \& Haluzik M 2014 The role of adipose tissue immune cells in obesity and low-grade inflammation. Journal of Endocrinology 222 R113-R127. (https://doi.org/10.1530/JOE-14-0283)

Mukhopadhyay R, Jia J, Arif A, Ray PS \& Fox PL 2009 The GAIT system: a gatekeeper of inflammatory gene expression. Trends in Biochemical Sciences 34 324-331. (https://doi.org/10.1016/j.tibs.2009.03.004)

Muro E, Atilla-Gokcumen GE \& Eggert US 2014 Lipids in cell biology: how can we understand them better? Molecular Biology of the Cell 25 1819-1823. (https://doi.org/10.1091/mbc.e13-09-0516)

Nelson ER, DuSell CD, Wang X, Howe MK, Evans G, Michalek RD, Umetani M, Rathmell JC, Khosla S, Gesty-Palmer D, et al. 2011 The oxysterol, 27-hydroxycholesterol, links cholesterol metabolism to bone homeostasis through its actions on the estrogen and liver $\mathrm{X}$ receptors. Endocrinology 152 4691-4705. (https://doi.org/10.1210/ en.2011-1298)

Newsholme P, Curi R, Gordon S \& Newsholme EA 1986 Metabolism of glucose, glutamine, long-chain fatty acids and ketone bodies by murine macrophages. Biochemical Journal 239 121-125. (https://doi. org/10.1042/bj2390121)

O'Neill LAJ, Kishton RJ \& Rathmell J 2016 A guide to immunometabolism for immunologists. Nature Reviews Immunology $16553-565$.

Oishi Y, Spann NJ, Link VM, Muse ED, Strid T, Edillor C, Kolar MJ, Matsuzaka T, Hayakawa S, Tao J, et al. 2017 SREBP1 contributes to resolution of pro-inflammatory TLR4 signaling by reprogramming fatty acid metabolism. Cell Metabolism 25 412-427. (https://doi. org/10.1016/j.cmet.2016.11.009)

Oren R, Farnham AE, Saito K, Milofsky E \& Karnovsky ML 1963 Metabolic patterns in three types of phagocytizing cells. Journal of Cell Biology 17 487-501. (https://doi.org/10.1083/jcb.17.3.487)

Osborn O, Oh DY, McNelis J, Sanchez-Alavez M, Talukdar S, Lu M, Li P, Thiede L, Morinaga H, Kim JJ, et al. $2012 \mathrm{G}$ protein-coupled receptor 21 deletion improves insulin sensitivity in diet-induced obese mice. Journal of Clinical Investigation 122 2444-2453. (https://doi. org/10.1172/JCI61953)

Ouchi N, Kihara S, Funahashi T, Matsuzawa Y \& Walsh K 2003 Obesity, adiponectin and vascular inflammatory disease. Current Opinion in Lipidology 14 561-566. (https://doi.org/10.1097/00041433200312000-00003)

Ouchi N, Higuchi A, Ohashi K, Oshima Y, Gokce N, Shibata R, Akasaki Y, Shimono A \& Walsh K 2010 Sfrp5 is an anti-inflammatory adipokine that modulates metabolic dysfunction in obesity. Science 329 454-457. (https://doi.org/10.1126/science.1188280)

Ouchi N, Parker JL, Lugus JJ \& Walsh K 2011 Adipokines in inflammation and metabolic disease. Nature Reviews Immunology $\mathbf{1 1}$ 85-97. (https://doi.org/10.1038/nri2921)

Patsoukis N, Bardhan K, Chatterjee P, Sari D, Liu B, Bell LN, Karoly ED, Freeman GJ, Petkova V, Seth P, et al. 2015 PD-1 alters T-cell metabolic reprogramming by inhibiting glycolysis and promoting lipolysis and fatty acid oxidation. Nature Communications 66692. (https://doi.org/10.1038/ncomms7692)

Popkin BM, Adair LS \& Ng SW 2012 Now and then: the global nutrition transition: the pandemic of obesity in developing countries. Nutrition Reviews 70 3-21. (https://doi.org/10.1111/j.1753-4887.2011.00456.x)
Posokhova EN, Khoshchenko OM, Chasovskikh MI, Pivovarova EN \& Dushkin MI 2008 Lipid synthesis in macrophages during inflammation in vivo: effect of agonists of peroxisome proliferator activated receptors alpha and gamma and of retinoid $\mathrm{X}$ receptors. Biochemistry 73 296-304. (https://doi.org/10.1134/ S0006297908030097)

Rambold AS, Cohen S \& Lippincott-Schwartz J 2015 Fatty acid trafficking in starved cells: regulation by lipid droplet lipolysis, autophagy, and mitochondrial fusion dynamics. Developmental Cell 32 678-692. (https://doi.org/10.1016/j.devcel.2015.01.029)

Ritchie RH, Zerenturk EJ, Prakoso D \& Calkin AC 2017 Lipid metabolism and its implications for type 1 diabetes-associated cardiomyopathy. Journal of Molecular Endocrinology 58 R225-R240. (https://doi. org/10.1530/JME-16-0249)

Ryo M, Nakamura T, Kihara S, Kumada M, Shibazaki S, Takahashi M, Nagai M, Matsuzawa Y \& Funahashi T 2004 Adiponectin as a biomarker of the metabolic syndrome. Circulation Journal $\mathbf{6 8}$ 975-981. (https://doi.org/10.1253/circj.68.975)

Saponaro C, Gaggini M, Carli F \& Gastaldelli A 2015 The subtle balance between lipolysis and lipogenesis: a critical point in metabolic homeostasis. Nutrients 7 9453-9474. (https://doi.org/10.3390/ nu7115475)

Shao W \& Espenshade PJ 2012 Expanding roles for SREBP in metabolism. Cell Metabolism 16 414-419. (https://doi.org/10.1016/j. cmet.2012.09.002)

Shimano H \& Sato R 2017 SREBP-regulated lipid metabolism: convergent physiology - divergent pathophysiology. Nature Reviews Endocrinology 13 710-730. (https://doi.org/10.1038/nrendo.2017.91)

Shoelson SE, Lee J \& Yuan M 2003 Inflammation and the IKK beta/I kappa B/NF-kappa B axis in obesity- and diet-induced insulin resistance. International Journal of Obesity and Related Metabolic Disorders 27 Suppl 3 S49-S52. (https://doi.org/10.1038/sj. ijo.0802501)

Smith K 2013 Liver disease: Kupffer cells regulate the progression of ALD and NAFLD. Nature Reviews Gastroenterology and Hepatology 10503. (https://doi.org/10.1038/nrgastro.2013.140)

Tang T, Sui Y, Lian M, Li Z \& Hua J 2013 Pro-inflammatory activated Kupffer cells by lipids induce hepatic NKT cells deficiency through activation-induced cell death. PLOS ONE 8 e81949. (https://doi. org/10.1371/journal.pone.0081949)

Tannahill GM, Curtis AM, Adamik J, Palsson-McDermott EM, McGettrick AF, Goel G, Frezza C, Bernard NJ, Kelly B, Foley NH, et al. 2013 Succinate is an inflammatory signal that induces IL-1beta through HIF-1alpha. Nature 496 238-242. (https://doi.org/10.1038/ nature11986)

Tie F, Banerjee R, Conrad PA, Scacheri PC \& Harte PJ 2012 Histone demethylase UTX and chromatin remodeler BRM bind directly to CBP and modulate acetylation of histone H3 lysine 27. Molecular and Cellular Biology 32 2323-2334. (https://doi.org/10.1128/ MCB.06392-11)

Umetani M, Ghosh P, Ishikawa T, Umetani J, Ahmed M, Mineo C \& Shaul Philip W 2014 The cholesterol metabolite 27-hydroxycholesterol promotes atherosclerosis via proinflammatory processes mediated by estrogen receptor alpha. Cell Metabolism 20 172-182. (https://doi.org/10.1016/j.cmet.2014.05.013)

van Diepen JA, Berbee JF, Havekes LM \& Rensen PC 2013 Interactions between inflammation and lipid metabolism: relevance for efficacy of anti-inflammatory drugs in the treatment of atherosclerosis. Atherosclerosis 228 306-315. (https://doi.org/10.1016/j. atherosclerosis.2013.02.028)

Wan J, Benkdane M, Teixeira-Clerc F, Bonnafous S, Louvet A, Lafdil F, Pecker F, Tran A, Gual P, Mallat A, et al. 2014 M2 Kupffer cells promote M1 Kupffer cell apoptosis: a protective mechanism against alcoholic and nonalcoholic fatty liver disease. Hepatology $\mathbf{5 9}$ 130-142. (https://doi.org/10.1002/hep.26607) 
Wang R, Dillon CP, Shi LZ, Milasta S, Carter R, Finkelstein D, McCormick LL, Fitzgerald P, Chi H, Munger J, et al. 2011 The transcription factor Myc controls metabolic reprogramming upon $\mathrm{T}$ lymphocyte activation. Immunity 35 871-882. (https://doi. org/10.1016/j.immuni.2011.09.021)

Whelan J, Gowdy KM \& Shaikh SR 2016 N-3 polyunsaturated fatty acids modulate B cell activity in pre-clinical models: Implications for the immune response to infections. European Journal of Pharmacology $\mathbf{7 8 5}$ 10-17. (https://doi.org/10.1016/j.ejphar.2015.03.100)

Worby CA \& Dixon JE 2011 Glycogen synthase: an old enzyme with a new trick. Cell Metabolism 13 233-234. (https://doi.org/10.1016/j. cmet.2011.02.006)

Wrann CD, Laue T, Hübner L, Kuhlmann S, Jacobs R, Goudeva L \& Nave H 2012 Short-term and long-term leptin exposure differentially affect human natural killer cell immune functions. American Journal of Physiology: Endocrinology and Metabolism 302 E108-E116. (https:// doi.org/10.1152/ajpendo.00057.2011)

Xu L, Kim JK, Bai Q, Zhang X, Kakiyama G, Min HK, Sanyal AJ, Pandak WM \& Ren S 2013a 5-Cholesten-3beta,25-diol 3-sulfate decreases lipid accumulation in diet-induced nonalcoholic fatty liver disease mouse model. Molecular Pharmacology 83 648-658. (https:// doi.org/10.1124/mol.112.081505)

Xu X, So JS, Park JG \& Lee AH $2013 b$ Transcriptional control of hepatic lipid metabolism by SREBP and ChREBP. Seminars in Liver Disease 33 301-311. (https://doi.org/10.1055/s-0033-1358523)

Xu H, Hertzel AV, Steen KA, Wang Q, Suttles J \& Bernlohr DA 2015 Uncoupling lipid metabolism from inflammation through fatty acid binding protein-dependent expression of UCP2. Molecular and Cellular Biology 35 1055-1065. (https://doi.org/10.1128/MCB.01122-14)

Yang QH, Hu SP, Zhang YP, Ping HH, Yang HW, Chen TY \& Liu HT 2012 Effects of different therapeutic methods and typical recipes of Chinese medicine on activation of c-Jun N-terminal kinase in kupffer cells of rats with fatty liver disease. Chinese Journal of Integrative Medicine 18 769-774. (https://doi.org/10.1007/s11655-0110691-5)

Zeng L, Tang WJ, Yin JJ \& Zhou BJ 2014 Signal transductions and nonalcoholic fatty liver: a mini-review. International Journal of Clinical and Experimental Medicine 7 1624-1631.

Received in final form 30 May 2018

Accepted 4 June 2018

Accepted Preprint published online 6 June 2018 